\title{
In house expertise
}

\author{
Orin Herskowitz
}

Executive-in-residence programs place world-class business advice within easy reach of aspiring bioentrepreneurs.

magine you are looking to launch a startup on what you believe to be transformative science emerging from your laboratory. What if you could tap into the experience of people like the former CEO of UnitedHealthcare (New York), a premier venture capitalist from Foundation Medical Partners (Norwalk, CT, USA), an entrepreneur who sold their medical device startup to GE Healthcare (Waukesha, WI, USA), or former senior R\&D executives from Merck (Kenilworth, NJ, USA), Sanofi (Paris) and Johnson \& Johnson (New Brunswick, NJ, USA)? Or better yet, what if you could speak to all of them, together, to help perfect your pitch, review your marketing strategy or ask for guidance in technology validation; what if they offered to provide advice on your intellectual property (IP) strategy or to give you blunt, objective and thorough feedback on your idea? And what if this advice came for free? Sound like a dream?

It is actually reality at dozens of universities across the United States and around the world, including at New York's Columbia University. In fact, the unnamed bearers of the titles mentioned above have been participants in our Columbia Technology Ventures (CTV) Executives-in-Residence (XIR) program over the past few years. Every semester, five or six senior executives, serial entrepreneurs and venture investors join our community and meet with faculty and student researchers to provide advice, to help them make connections and generally be as helpful as they can in the name of technology commercialization. They also make themselves available to my team at the tech transfer office to review new inventions, provide input on technology marketing campaigns,

Orin Herskowitz is VP of Tech Transfer and Intellectual Property at Columbia Technology Ventures at Columbia University, New York, New York, USA.

e-mail:orin.herskowitz@columbia.edu review potential licensing deal terms and help with critical patent decisions.

Similar programs exist at institutions such as the University of Washington, University of California, Los Angeles, University of Michigan, University of Minnesota and Boston University (Table 1). If your school does not have an XIR program, you may want to consider starting one.

\section{Realizing your problem}

CTV is the tech transfer office of Columbia University. CTV's core objective is to facilitate the transfer of inventions from academic research to outside organizations for the benefit of society on a local, national and global basis. Each year, CTV manages about 400 invention disclosures (about half in the life sciences) that emerge from the $\sim \$ 800$ million in sponsored research funding that moves into Columbia's research laboratories annually. Roughly $60 \%$ of these inventions are the subject of at least a provisional patent application, and these applications (and awards) eventually result in more than 100 license deals and roughly 20 new IP-backed startups every year.

In addition to licensing IP to established companies, CTV has a particular focus on startup companies, and, over the years has been involved with launching $>180$ companies based on Columbia's research. Of those, $>40$ have received venture capital funding, and $>25$ of those have been acquired or launched initial public offerings to date. Between straight patent licensing and equity exits, CTV has historically done well with tech transfer revenue-more than $\$ 100$ million annually for the past several years. That revenue, in turn, is shared with the inventors, and the remainder goes on to fund further investments in the research infrastructure and initiatives at the university.

That's all great news, but behind the scenes, managing the outcomes for our researchers and their technologies had become increasingly complicated and challenging. As at many large institutions, life sciences researchers at Columbia's Medical Center, Engineering and Arts \& Sciences programs generate a highly

\begin{tabular}{|c|c|c|}
\hline Arizona State University & Mount Sinai Health System & $\begin{array}{l}\text { University of California, Los } \\
\text { Angeles }\end{array}$ \\
\hline Boston University & $\mathrm{NIH}$ & University of Cambridge \\
\hline Children's National Health System & Northwestern University & University of Chicago \\
\hline Columbia University & Oregon Health \& Science University & University of Cincinnati \\
\hline Eastern Michigan University & Princeton & University of Georgia \\
\hline Georgia State University & $\begin{array}{l}\text { South Dakota School of Mines \& } \\
\text { Technology }\end{array}$ & University of Maryland \\
\hline Johns Hopkins University & SUNY Buffalo & University of Michigan \\
\hline Medical College of Wisconsin & Texas Tech & University of Minnesota \\
\hline Michigan State University & University of Akron & University of Missouri \\
\hline Moffitt Cancer Center & University of Alabama, Birmingham & University of Montana \\
\hline University of Pittsburgh & $\begin{array}{l}\text { University of Texas Health Science } \\
\text { Center }\end{array}$ & University of Virginia \\
\hline University of Washington & $\begin{array}{l}\text { University of Wisconsin, Madison } \\
\text { (WARF) }\end{array}$ & $\begin{array}{l}\text { University of Wisconsin, } \\
\text { Milwaukee }\end{array}$ \\
\hline Washington State University & Yale University & \\
\hline
\end{tabular}


a

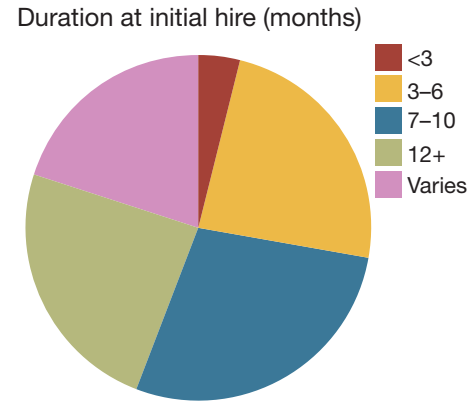

C

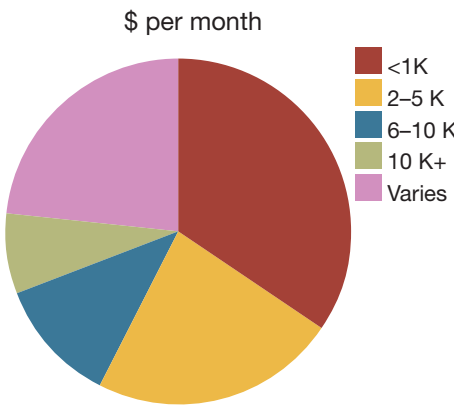

b

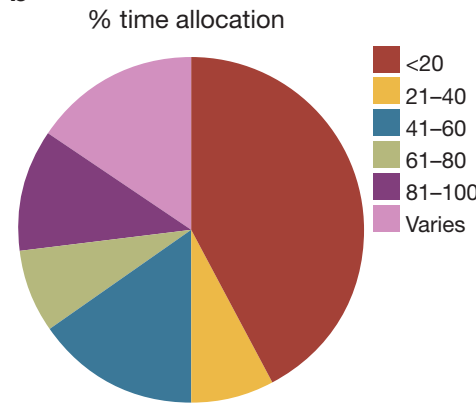

d

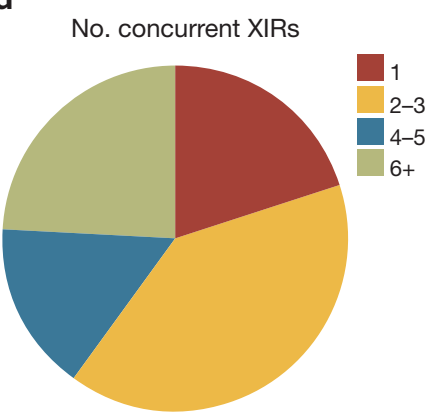

Figure 1 All the ways to XIR. (a) Duration of initial hire. (b) Percentage of full time employee commitment. (c) Monthly payment to XIR. (d) Number of XIRs working at institute at the same time. Data are from responses of 23 institutions to a survey conducted in 2013 by the Association of University Technology Managers.

diverse set of inventions. This was something we were accustomed to. However, in recent years, we had seen an explosion of growth in cross-disciplinary inventions: robotic surgery tools from collaborating surgeons and software engineers; tools for humanitarian relief designed by architects and mechanical engineers; nextgeneration DNA sequencing platforms from chemical and electrical engineers.

Columbia's tech transfer office staff was already large and relatively experienced, but we didn't have enough in-house expertise to incubate these myriad projects through to completion. By 2010, we realized that we had a problem. We needed external experts for advice when the school made key patent decisions in areas we might not be intimately familiar with. We needed context on appropriate deal structures and terms for increasingly specialized industries, such as nutraceuticals, food additives and imaging algorithms. We wanted introductions to inlicensing executives in these changing fields, and we needed help navigating the increasingly complex regulatory and reimbursement landscape. We needed to know more about how biopharma companies manage drug discovery and development. Finally, we required experienced entrepreneurs who could come to the school and work with faculty and student startup teams on their business model canvases and practice pitches, and help them make connections with investors for the best of these opportunities.
We started thinking about solutions and immediately ruled out adding permanent staff, primarily because appropriate people would likely be too expensive on a full- or part-time basis, but also because any single individual wouldn't have the very broad expertise we desired. We briefly experimented with professional 'expert networks', which offer access to extremely skilled individuals on an hourly basis. However, these services typically charge upfront fees that were prohibitive for an academic institution. Furthermore, we found that the brief (1-2 h), transactional nature of interactions with the hired experts were not going to lead to satisfying insights. Thus, we focused on an in-house XIR program.

\section{Columbia's Executives-in-Residence}

Although this approach has worked well for us, an XIR program can be run in many ways. We conducted a survey in 2013 of 26 institutions running similar programs, and we found that there was an array of approaches to handling compensation, workload and contract duration, and a variety of ways to put XIRs to good use (Figs. 1 and 2; email author for full results.)

Although every institution seems to have developed their own style of XIR program, I would describe programs as falling into two main types of consulting engagements. One version, which I will call the 'Quora' model, relies on a large number of loosely affiliated, part-time, short-term experts compensated at levels comparable to academic honoraria. The other model is more like the 'McKinsey' model: full or nearly full-time experts who stay with the tech transfer office longer and are paid an industry-equivalent full-time salary. We initially built ours on the McKinsey model in 2011, but have migrated to the Quora model over time, and it's likely the program will evolve further.

Not every one of our XIR engagements has been perfect, but we have found the program to be quite beneficial for our office. Some XIRs have a deep understanding of IP and business development, and thus CTV's licensing team has employed them for crafting marketing materials, identifying relevant companies for licensing, making introductions to contacts giving advice on deal terms and helping with keep-or-kill patent decisions. Those who have launched and sold multiple startups have been invaluable sounding boards for the dozens of startups launched across Columbia each year. Those with biopharma industry experience have been particularly helpful in guiding Columbia's early-stage drug discovery efforts and providing sage counsel on the challenges of the regulatory process. By having a rotating cast of characters, we can serve a wider variety of faculty and student innovators from across disciplines over the course of any given year.

The program has also paid dividends in surprising ways. In addition to the engagement with our technologies and our startups, our XIRs have been a great source for ideas on how our tech transfer office could improve overall. They have suggested changes to our website, to the forms the faculty fill out to describe their new inventions, to our marketing templates, to our standard deal structures and terms, and even to our organizational strategies. Perhaps best of all, all our XIRs have remained loyal 'friends of Columbia' after leaving the program, continuing to provide advice and bolstering our reputation in the community for years to come.

\section{Recipe for success}

We have found some critical factors that have contributed to the success of our program. Each of these are discussed in turn below.

Who to hire. We contract four to six XIRs per year, looking to form a group with a broad enough set of experiences and expertise to cover all of our primary invention areas. Typically, XIRs are successful entrepreneurs, industry executives or investors, usually ones who just wrapped up their last adventure (e.g., they sold their company, invested their fund or received a post-merger buyout package), but haven't quite decided what they want to do next. These executives often aren't ready 
to commit to a long engagement, which might inadvertently preclude seizing a new opportunity when one comes along, but they will sign shorter contracts.

We find the process works best with local candidates, even though XIR interactions often end up being conducted by phone or e-mail. If XIRs are able to just 'swing by' and meet a team on short notice, they will find it easier to get fully engaged in a project.

Similarly, although most of the XIR's value comes from business and operational experience, we've found that selecting XIRs with at least a moderate technical background makes things easier. A scientific background seems to allow XIRs to 'fall in love' with a given project and also facilitates their getting up to speed quickly across a wide array of projects throughout their term. This doesn't mean that each XIR needs a $\mathrm{PhD}$ or ten years in a research role, but having enough technical savvy to be able to quickly grasp the key scientific merits of the invention has proved helpful.

It's important to note that for every XIR we engage, there are roughly an equal number that we decline. If seeking to hire an XIR, you'll likely find a cohort of alumni, community members or friends of the university who are very enthusiastic about joining, but for whatever reason (experience, expertise or style) are not appropriate matches for your program. At Columbia, we do informal reference checks on every potential XIR and have them meet the entire licensing team before we make a commitment, even to the first three months. If the XIR doesn't appear to have a level of technical depth or the right cultural fit with academia, or has unrealistic expectations about the level of support they will receive, we politely decline to proceed. Yes, some of those declines have been uncomfortable, but we believe it would have been far worse if we had proceeded despite our reservations.

We recognize that we benefit from the New York City area being relatively dense with exactly the kinds of candidates we try to attract and also that the Columbia University brand is quite well known. This helped us get off the ground, though certainly in the early days of the program we had to aggressively seek out our XIRs. As the program has become better established, however, we found our next XIRs approaching us directly, either through referrals from our faculty, our former XIRs or people in our personal networks. Other universities have reported success finding XIRs by actively mining alumni networks, by placing newspaper advertisements, spreading the word by means of social media, hiring recruiters with domain expertise, and working with local economic development organizations

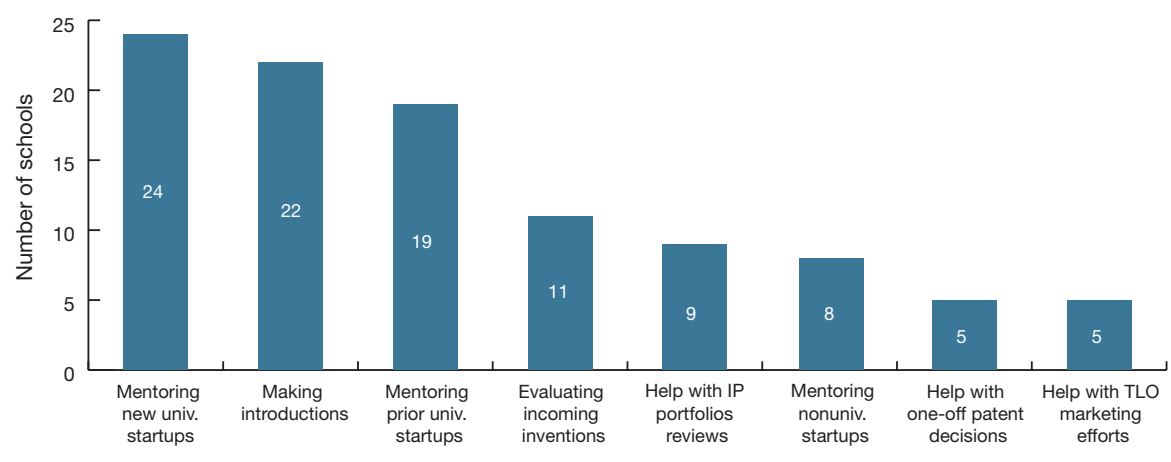

Figure 2 Tasks to which 23 XIR programs put their XIRs to work (in addition to launching startups).

and trade associations. All are fruitful avenues to explore.

How to structure. From our perspective, the ideal XIR life cycle seems to be six to nine months. We contract XIRs at the start for three months, but leave it extendable in three-month increments-a nonthreatening way to get them engaged. After three months, most report that they have only just started to figure out how tech transfer works, dig into the IP portfolio and hit their stride, and thus we agree to extend the engagement. After nine months, most have already provided input on the projects within their areas of expertise, and their utilization rate on campus starts to drop. Accordingly, with fewer projects in the queue needing their attention, they usually start to think about their next adventure and typically step down.

This three-month increment also allows a nonrecriminatory separation if an XIR doesn't quite work out because it is a lot easier to not renew someone than to terminate them early. We have been fortunate in this area: so far, weve only had one person not finish the three-month assignment, and in that case it was for an ideal outcome-they left to become CEO of one of our startups!

Each contracted XIR commits to about one day per week, though each month we have one day when all the XIRs lunch as a group, debrief one another on their projects and hear pitches together. For the remaining $\sim 20 \mathrm{~h}$ per month, the XIRs make themselves available as needed to the tech transfer staff, our university inventors, or our startups, by phone, e-mail or live meetings.

Managing XIRs is simplified by hiring in cohorts (as opposed to rolling start dates). We now bring XIRs in with the start of the academic year, and add people only in the spring and then only if a particularly compelling opportunity arises. This hiring in groups requires only one round of training, one set of introductions to the research community, a shared learning curve and a more cohe- sive group dynamic. We also heard from our XIRs that networking within the group was a substantial advantage to them, and that they enjoyed the creativity that came from the group brainstorming sessions.

Other institutions have set compensation levels differently, but for us, our experts provide their services to Columbia for little more than travel expenses: borrowing language from the Columbia XIR document, our XIRs get paid " $\$ 1,000$ per month and all the Diet Coke they can drink." Certainly these experienced executives with demanding schedules do not do this for the money $-\$ 1,000$ per month is well below their normal pay grade. Even if XIRs of this caliber do not 'need' the money, we believe that officially offering them compensation has led to a greater engagement and willingness to dig in. Whether more or less compensation would achieve the same results is hard to say.

Once we've settled on our candidates, we insist on a full nondisclosure and limited IP assignment agreement. The latter document in particular ensures that, should the XIRs make an inventive contribution to a Columbia research project solely by virtue of their XIR role, they explicitly waive any rights to that invention without any expectation of further compensation. We also have all XIRs sign a 'rules of engagement' document, outlining our mutual expectations. Taken together, these documents allow our researchers to feel comfortable speaking freely in meetings about confidential matters without any concerns about intellectual property. (All of these documents are available upon request to the author's email.)

Although these XIR programs do not require new facilities or a massive budget increase, a certain amount of infrastructure is required. You'll need a central scheduling resource to coordinate everyone's calendars, so that XIRs can plan and meet with teams quickly and conveniently. Your XIRs will need access to spare desks so they can be productive on campus in between meet- 
ings, and occasionally they may need access to conference rooms.

Part of your XIR's responsibility will be to navigate the school's IP portfolio and scout for opportunities. Providing them access to the junior analysts or licensing assistants can help the XIRs do this quickly and easily and can pay dividends. And part of the benefit of the program is the chance for the tech transfer office's senior team to get to know these highpowered execs, and vice versa. That means that, at a minimum, participation by the tech transfer office directors in group meetings is critical to drive success on both sides.

\section{Conclusions}

Our XIR approach has worked well for us, but as mentioned earlier, there are many ways to run such a program. The 'right' approach will depend on a variety of factors: budget; diversity of scientific disciplines covered; ability to attract top-tier talent; and degree of entrepreneurial energy on campus. I would encourage all institutions to review the survey material at the link I provided, find a model that works for you and then keep iterating over time. If you find a particularly good approach not mentioned above, please e-mail me so Columbia and the rest of the university community can learn from your success!

\section{COMPETING FINANCIAL INTERESTS}

The author declares no competing financial interests.

\section{First Rounders Podcast: Rachel King}

Rachel King is president and CEO of GlycoMimetics and former chairwoman of the Biotechnology Innovation Organization. Talking with Nature Biotechnology, King discusses gene therapy, how a CEO handles layoffs and growing up with chickens. http://www. nature. com/nbt/podcast/index.html

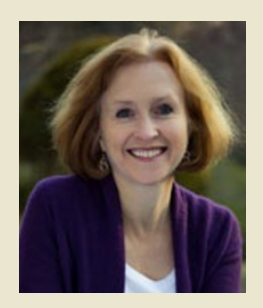

